\title{
Promotion of electronic cigarettes: tobacco marketing reinvented?
}

\author{
Electronic cigarettes are not subject to the same marketing controls as tobacco products. Marisa \\ de Andrade, Gerard Hastings, and Kathryn Angus argue that their advertising is likely to appeal \\ to young people and undermine tobacco control policy
}

\author{
Marisa de Andrade research fellow ${ }^{13}$, Gerard Hastings professor ${ }^{123}$, Kathryn Angus researcher ${ }^{13}$ \\ ${ }^{1}$ Institute for Social Marketing, University of Stirling, Stirling FK9 4LA, UK; ${ }^{2}$ Centre for Tobacco Control Research, University of Stirling ; ${ }^{3} \mathrm{UK}$ Centre \\ for Tobacco and Alcohol Studies, University of Stirling
}

The market in electronic cigarettes (e-cigarettes) has grown rapidly over the past few years. Many small manufacturers have emerged, and the tobacco industry has also taken an active interest in the sector, buying up independent operators and openly strategising about the business opportunities. Press releases show that 121 product trademark applications were made in the UK alone between May 2012 and June 2013. ${ }^{1}$

This growth has been accompanied by increased marketing. The UK spend on e-cigarette promotion and related smoking materials increased from $£ 1.7 \mathrm{~m}$ ( $€ 2 \mathrm{~m} ; \$ 2.8 \mathrm{~m}$ ) in 2010 to $£ 13.1 \mathrm{~m}$ in 2012. This increase is likely to continue as the tobacco industry gets more involved. In 2013, a British American Tobacco subsidiary spent $£ 3.6 \mathrm{~m}$ in just 2 months to promote its Vype e-cigarette in the UK market and Lorillard, the US tobacco multinational, which spent $£ 19$ m promoting its e-cigarette Blu in the United States, acquired the UK e-cigarette brand Skycig. $^{23}$

Concern has already been expressed about these developments. The National Institute for Health and Care Excellence notes that e-cigarettes "could, without regulation, be marketed in a way that may ultimately promote smoking, ${ }^{4}$ and researchers have highlighted the need to monitor e-cigarette marketing. ${ }^{5-8}$ An analysis of e-cigarette coverage in the UK and Scottish press from 2007 to 2012 showed that newspaper stories often describe the products as a way of getting around smoke-free legislation and glamorise use through association with celebrities. ${ }^{9} \mathrm{We}$ were commissioned by Cancer Research UK to study e-cigarette marketing and media coverage in the UK from May 2012 to June 2013, during the period when the Medicines and Healthcare Products Regulatory Authority was considering regulation of the products as medicines. We searched for mentions of e-cigarettes in the database Nexis UK, which holds the text content of UK national and local newspapers, as well as in trade press, tobacco journals, and television advertising (see web appendix). We also analysed the use of five social networking sites by seven leading e-cigarette brands over 40 days. Full details of the methods and results have been published. ${ }^{1}$ Here we use examples from the study to show how e-cigarettes are being marketed to the general public and policy makers.

\section{What is being marketed to consumers?}

Marketing falls into two categories: consumer marketing aimed at the general public and stakeholder marketing aimed at policy makers and public health bodies. Consumer marketing is taking many forms, including television commercials, sports and cultural sponsorship, celebrity endorsement, social networking, online advertising, point of sale displays, pricing strategies, and product innovation. The line between editorial and paid advertising is blurred by public relations activity. For example, we found public opinion surveys commissioned by manufacturers, overt lobbying asking consumers to "copy and paste" correspondence to politicians that urged them to reject regulation, and one brand sponsoring a university lecture on e-cigarettes to "explain what they are, how they work, whether they help people stop smoking and whether they are safe."

\section{Unsubstantiated or overstated claims}

Safety and cessation are key marketing themes aimed at smokers. E-cigarettes are described in newspaper articles and advertisements as "a safer and much cheaper method to satisfy a nicotine addiction," a "healthier alternative," and "harmless." They are also promoted as "an indispensable tool in the pathway to quitting." Although there is some evidence that e-cigarettes are safer than conventional ones and can help with cessation, ${ }^{10} 11$ the Advertising Standards Authority judged that some marketing claims went beyond the available evidence. ${ }^{12}$ However, these claims continued to appear in both advertising and editorial after the rulings. 


\section{Dual use}

E-cigarette marketing is also promoting long term use as a permanent alternative to tobacco, and a temporary one in public places where smoking is banned. Thus adverts and editorials promote "the freedom to enjoy the personal pleasures associated with smoking in places where traditional smoking has been banned." One company emphasised this by registering its e-cigarette under the trademark Lite-Up Anywhere, and another promoted dual use, saying that its "smart plastic case [is] designed to fit snuggly in the pocket, protect the e-cig, and even house one regular tobacco cigarette for those adult smokers who chose to dual between the two."

\section{Glamour, youth, and new users}

Some e-cigarettes are being promoted as a lifestyle choice and statement of identity (figure $\Downarrow$ ). This advertising is backed by stylish design and association with celebrity and fashionable venues and events. E-cigarette companies are sponsoring sporting events and using the resulting promotional opportunities such as team kit advertising and free samples at events. Thus Nicolites announced on Facebook that it is "happy and excited to say we are now the principle [sic] partners for Birmingham City Football Club.” Similarly, publicity around E-Lites' sponsorship of the British Superbike Championship said that its red and white branding was "reminiscent of the iconic branding which was famously associated with motorsport throughout the 1980s." The company's chief executive explained to a retail trade magazine that he is "delighted to be ... partnering with a sport that was once synonymous with tobacco sponsorship [as a] way of raising awareness that smoking has been reinvented."

Celebrity endorsement in the media-through paid-for testimonials or having their name or image linked to a product-is common (box), resulting in references to stars such as Girls Aloud "puffing on e-cigarettes to cope with the stress of their 10th anniversary tour." Images of celebrity users and product endorsements are then posted on social media platforms and linked to brand websites and online feeds.

Independent e-cigarette companies and the tobacco industry are promoting products as not only socially acceptable but socially superior, and in the process developing an entirely "new subculture." Facebook pages for e-cigarette brands include pictures of consumers posing with e-cigarettes with captions such as "MAX-imum style" and articles on "10 ways to look cooler while vaping an e-cigarette." Vapestick has created a retro-style computer game called Electronic Cigarette Wars.

\section{Product innovation}

Companies are offering e-cigarettes in various colours and flavours and ones that are nicotine-free. Blu promoted an innovative "smart pack" that alerts you to other users within 15 metres-both packs vibrate, flash, and transmit Facebook and Twitter profiles - while Skycig introduced an "exclusive black lightning design with electric yellow tip" for its nicotine-free e-cigarette with the "active ingredient taurine," which it claimed "takes e-cigs to a whole new level."

Smoking shisa pens is described in the Daily Mail and Edinburgh Evening News as "one of the trendiest new activities among the hip fashionable young crowd in the UK," and "the latest healthier alternative designed to replicate the sociable custom [of smoking] minus the carcinogens and addictive nicotine," with "flavoured fumes [that] taste more like children's sweets than any sort of smoke substitute." Online price discounts are offered through social media — for example, a Facebook page announces: "V-Shisha sunshine promo!! Save $20 \%$... off our 5-pack of $0 \%$ nicotine, fruity and sparkly disposables."

\section{What is being marketed at policy makers?}

E-cigarettes, and the harm reduction approach they represent, are providing a useful tool for targeting anti-smoking stakeholders. As a tobacco industry spokesperson explains in a tobacco industry trade journal: "business objectives and public health objectives can be aligned for the best outcome . . . if all involved recognise that harm reduction, as opposed to prohibition, can become a meaningful part of an overall health strategy designed to reduce tobacco related disease. Government and industry can work together as partners." Companies are weaving public health pronouncements into marketing campaigns. An e-cigarette Facebook page stated: "NICE [National Institute for Health and Care Excellence] has become the first public institution to recommend the electronic cigarette for smokers who cannot quit"; another announced it was "proud to say the charity Action Smoking and Health have supported us in our partnership [the sponsorship of a football club]."

Nevertheless, companies generally worked to oppose the idea of medical regulation. Two independent brands, for example, organised petitions getting consumers to write to politicians to persuade them to oppose EU legislation that would have put controls on e-cigarettes.

A key outcome for e-cigarette companies and the tobacco industry is legitimacy. In a trade article, a tobacco industry analyst clarifies its benefits: "While cigarettes are being progressively being [sic] locked away in cupboards and under counters so that they cannot be seen by children, Tesco, the UK's leading retailer, has special stalls explicitly promoting a brand of e-cigarette." Similarly a company's chief executive explains that its e-cigarette acquisition "gives Lorillard a meaningful seat at the table in the harm reduction debate, and we intend to provide responsible leadership to this emerging category."

\section{Public health implications}

Large numbers of smokers switching from tobacco to safer nicotine sources has the potential to bring substantial public health gains. However, our audit shows that the commercial exploitation of e-cigarettes is threatening this promise in three ways.

Firstly, e-cigarettes are being promoted as lifestyle accessories using a combination of evocative advertising, sponsorship, and celebrity endorsement, all of which have an obvious appeal to young people. This risks non-smokers being pulled into nicotine use, a danger that is exacerbated by the development and promotion of products for first time use. Furthermore, many of these products replicate cigarettes so closely, both in appearance and how they are consumed, that vaping looks just like-and hence models-smoking. Even when the behaviour is unequivocally vaping, it still models the idea of nicotine self medication by inhaling a vapour into the lungs, along with the implication that there is another more dangerous way of doing this. This suggests the potential for e-cigarettes to inadvertently promote smoking.

Secondly, the marketing of e-cigarettes risks undermining wider tobacco control policies. The visual similarity between conventional and electronic cigarettes, as well as between smoking and vaping, means that e-cigarette advertising and point of sale activity can be mistaken for (the now outlawed) tobacco promotion. Similarly, the promotion of dual usage 


\section{Celebrity endorsement of e-cigarettes}

Characters on television programmes in the UK such as Eastenders and Lewis have used e-cigarettes, and the products are being promoted through features in shows such as the Alan Titchmarsh Show.

Similarly in the US, Hollywood celebrities have shown how they use e-cigarettes to help them quit on television talk shows. Actress Katherine Heigl, for example, used an e-cigarette while appearing on Live With David Letterman, claiming she was addicted to the product but it "wasn't bad for you," and encouraged Letterman to have a "puff."

Jonny Depp's character uses an e-cigarette in the feature film The Tourist. Other Hollywood celebrities including Leonardo DiCaprio, Dennis Quaid, and Kevin Connolly have also been photographed with e-cigarettes, and company websites feature pictures of A-list celebrities who use their products.

undermines one of the key health benefits of smoke-free legislation - the stimulus it gives smokers to quit.

Thirdly, the tobacco industry is moving into the e-cigarette market and using e-cigarettes and harm reduction to build links with public health, policy makers, and other stakeholders. This process is accelerating: a wholly owned subsidiary of British American Tobacco announced plans to license an alternative nicotine delivery device with the Medicines and Healthcare Products Regulatory Agency. This is jeopardising Article 5.3 of the Framework Convention on Tobacco Control, which requires that development and implementation of public health policy should be completely protected from industry influence. ${ }^{13}$ These problems demand a swift regulatory response. The Medicines and Healthcare Products Regulatory Agency's decision in June to regulate e-cigarettes as medicines acknowledges the need for controls, but these cannot wait for the three years it has proposed. Specifically young people need protection, marketing must to be tightly reined in, existing tobacco control policy reinforced, and the tobacco industry explicitly excluded from the policy making arena. One obvious first step would be to regulate e-cigarettes as tobacco products.

We thank Diane Dixon and Richard Purves for their contributions to the wider project.

Contributors and sources: The authors all have a long term research interest in examining critically the role of marketing in society. They have worked on various public health research projects related to tobacco, alcohol, food, and pharmaceuticals. MdA and GH conceptualised and designed the study and interpreted data. MdA and $\mathrm{KA}$ acquired and analysed data. MdA and GH drafted the manuscript; $\mathrm{KA}$ revised it. All authors approved the final version.

Competing interests: We have read and understood the BMJ policy on declaration of interests and declare that the study on which this article is based was funded by Cancer Research UK. The authors are members of the UK Centre for Tobacco and Alcohol Studies (www.ukctas.ac.uk) and have received funding from the British Heart Foundation, Cancer Research UK, the Economic and Social Research Council, the Medical Research Council, and the National Institute of Health Research, under the auspices of the UK Clinical Research Collaboration.

Provenance and peer review: Not commissioned; externally peer reviewed.

1 De Andrade M, Hastings G, Angus K, Dixon D, Purves R. The marketing of electronic cigarettes in the UK. 2013. www.cancerresearchuk.org/prod_consump/groups/cr_common/ @nre/@pol/documents/generalcontent/cr_115991.

2 Nicoventures secures a raft of listings for its Vype e-cigarettes. Grocer 2013 Nov 9. www. thegrocer.co.uk/fmcg/e-cigarette-vype-from-nicoventures-secures-raft-of-listings/351328. article.

3 Moon T. Tobacco returns to TV with e-cigarette "deterrent." International Business Times 2013 Sep 14. www.ibtimes.co.uk/articles/506072/20130914/e-cigarettes-tv-big-tobaccoadvertising-blu.htm.

4 National Institute for Health and Care Excellence.Tobacco: harm-reduction approaches to smoking. Public health guidance 45. 2013. www.nice.org.uk/nicemedia/live/14178/ 63996/63996.pdf.

5 De Andrade M, Hastings $\mathrm{G}$. Tobacco harm reduction and nicotine containing products: research priorities and policy directions.Cancer Research UK report. 2013. www. cancerresearchuk.org/prod_consump/groups/cr_common/@nre/@pol/documents/ generalcontent/tobacco-harm-reduction.pdf.

6 Grana RA. Electronic cigarettes: a new nicotine gateway? J Adolesc Health 2013;52:135-6. 7 E-cigarettes: a moral quandary. Lancet 2013:382:914.

8 Cobb NK, Brookover J, Cobb CO. Forensic analysis of online marketing for electronic nicotine delivery systems. Tob Control 2013 Sep 13 [Epub ahead of print].

9 Rooke C, Amos A. News media representations of electronic cigarettes: an analysis of newspaper coverage in the UK and Scotland. Tob Control 2013 Jul 24 [Epub ahead of print].

10 Goniewicz ML, Knysak J, Gawron M, Kosmider L, Sobczak A, Kurek J, et al. Levels of selected carcinogens and toxicants in vapour from electronic cigarettes. Tob Control. 2013 Mar 6. [Epub ahead of print].

11 Bullen C, Howe C, Laugesen M, McRobbie H, Parag V, Williman J, et al. Electronic cigarettes for smoking cessation: a randomised controlled trial. Lancet 2013;382:1629-37.

12 Committee of Advertising Practice (CAP). Electronic cigarettes. 2013. www.cap.org.uk/ Advice-Training-on-the-rules/Advice-Online-Database/Electronic-cigarettes.aspx

13 World Health Organization. WHO Framework Convention on Tobacco Control. 2005. http: //whqlibdoc.who.int/publications/2003/9241591013.pdf.

Cite this as: BMJ 2013;347:f7473

๑ BMJ Publishing Group Ltd 2013 
Figure

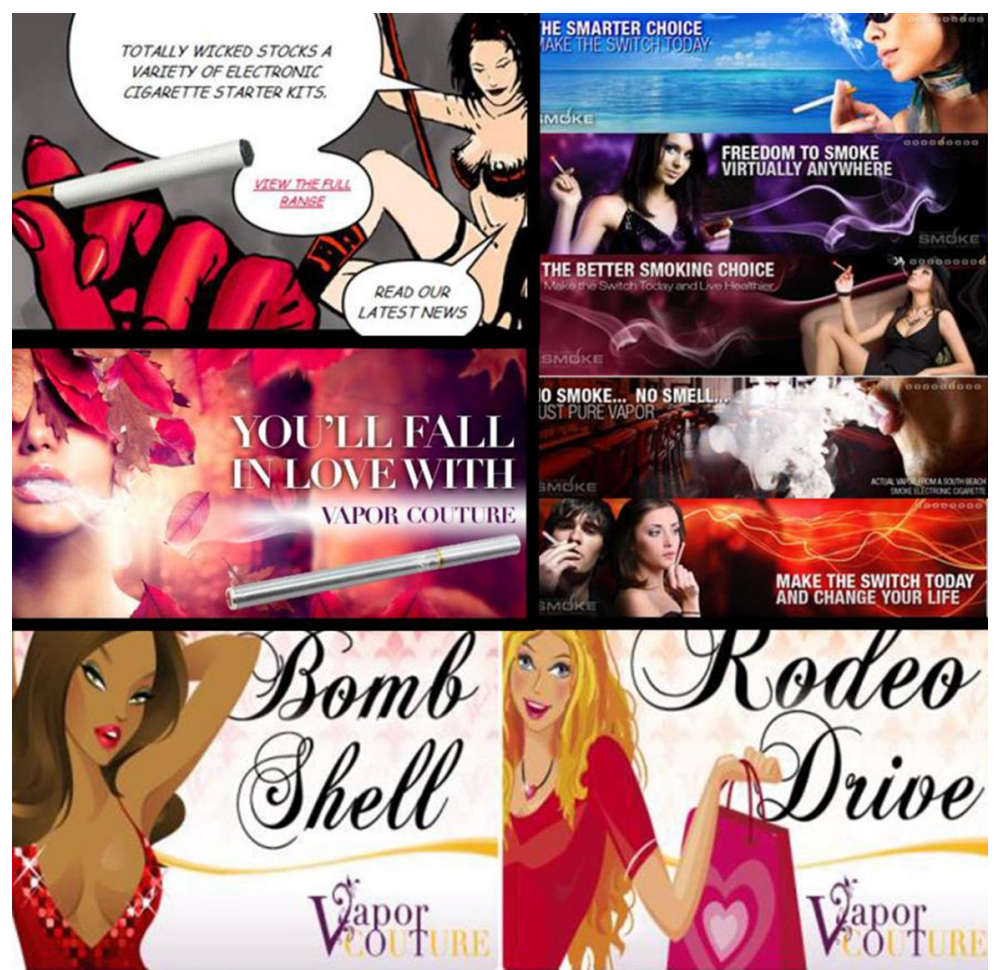

Examples of evocative images used in advertising of e-cigarettes in the UK and US 